\title{
O CIRCO VOADOR E O RESPEITÁVEL PÚBLICO
}

\author{
Fernando Eduardo Fernandes ${ }^{1}$
}

\section{Resumo:}

O texto aqui submetido se insere nos temas dos "percursos em campo". Refere-se mais precisamente a um dos dias de observação participante realizada na plateia do show de Rodrigo Amarante, na casa Circo Voador, no bairro da Lapa, Rio de Janeiro. O conteúdo se concentra na descrição de uma paisagem onde se deram gestos de indivíduos e grupos que escapam às idealizações teóricas mais simplistas. Por meio de observações como as que estão presentes neste relato foi possível dar base a uma construção conceitual de caráter mais contemporâneo e mais adequada ao aspecto efêmero, plástico e irônico das identidades de hoje.

Palavras-chave: expressividade, identidade, afastamento irônico, auto-reflexividade.

\begin{abstract}
:
The paper submitted here is inserted in the themes of "field trips". It refers more precisely to one of the days of participant observation realized in the audience of the show of Rodrigo Amarante, in the house Circo Voador, in the district of Lapa, Rio de Janeiro. The content focuses on the description of a landscape where took place gestures of individuals and groups that escape the most simplistic theoretical idealizations. By means of observations such as those present in this account, it was possible to base a conceptual construction of a more contemporary character and more adequate to the ephemeral, plastic and ironic aspect of today's identities.
\end{abstract}

Palavras-chave: expressiveness, identity, ironic whitdrawal, self-reflexity.

\footnotetext{
${ }^{1}$ Graduado em Licenciatura em Música pela Universidade Federal do Estado do Rio de Janeiro. Mestre em musicologia pelo Programa de Pós-graduação em Música pela Universidade Federal do Estado do Rio de Janeiro. Doutor em ciências sociais pelo Programa de Pós-graduação em Ciências Sociais da Universidade do Estado do Rio de Janeiro. Professor de história da música, história da arte e de instrumento musical (guitarra e violão). E-mail: ticofernandes@globo.com
} 


\section{Introdução}

O texto que se segue faz parte do diário de campo presente em minha tese de doutorado. Nele estão presentes relatos sobre as minhas observações participantes referentes ao show de Rodrigo Amarante (ex-Los Hermanos), realizado em novembro de 2014. Decidi disponibilizar o meu diário de campo no texto final da tese, na seção de anexos, com o objetivo de permitir que o leitor possa acompanhar as impressões subjetivas suscitadas graças ao meu contato com o ambiente e com as pessoas observadas. Os meus relatos sobre os dias da observação participante demonstram não apenas impressões subjetivas resultantes da experiência etnográfica, mas também se configura como um exercício teórico de comparação entre os conceitos sociológicos e antropológicos que lidam com a expressividade cotidiana.

Conceitos de Bourdieu, Goffman, Hochschild, Hall e de filósofos como Deleuze e Derrida foram comparados, relativizados e postos à prova de acordo com as peculiaridades dos diferentes grupos observados nos diferentes dias do trabalho de campo. O habitus bourdiesiano pareceu-me engessado demais diante do intercâmbio dos gestos vindos de outros contextos sociais; a "representação" goffmaniada mostrou-se fixa demais diante da efemeridade das expressões corporais de caráter mais irônico e brincalhão - os "atores" sociais não pareciam querer convencer a plateia de observadores com uma pretendida veracidade interior; tampouco a emocionalidade conscientemente engendrada de Hochschild pareceu-me isenta de problemas naquele contexto, pois a intelectualidade (e não apenas as emoções) serve também de motivação para os gestos e expressões dos agentes em eventos artísticos. Os shows observados se deram todos na casa de shows Circo Voador, no bairro da Lapa, no Rio de Janeiro. Este local, conhecido como ponto de convergência da intelectualidade alternativa carioca, tem a peculiaridade de receber pagantes que em grande parte são mais fiéis (ou mais fãs da) à casa de shows em si mesma do que aos artistas que lá se apresentam. Este dia do trabalho de campo foi um dos mais significativos para a construção do conceito de paródia expressiva, muito determinante nos capítulos finais da tese.

\section{Show de Rodrigo Amarante - novembro de 2014 - Circo Voador, RJ}

Assim que o Rodrigo Amarante e os músicos subiram no palco eu fui em direção à plateia central com o objetivo de ficar mais próximo do show, tanto fisicamente quanto emotivamente. Quis observar mais de perto a performance dos músicos, suas formas de expressão, suas técnicas instrumentais, em suma, sua atuação poética em sentido mais amplo. Pelo fato de ter sido um show de um artista pelo qual tenho bastante interesse, principalmente 
na fase de sua carreira solo, me permiti desta vez me posicionar menos "de fora". Foi o show, até então, em que me portei menos como observador. Creio que neste dia eu acionei e me portei mais de acordo com a minha identidade de músico e menos com a de cientista social. Ocupei outro nível de objetivação, quando busquei apreender mais o que ocorria no palco do que no local referente à atuação do público.

Em muitos momentos, resolvi assumir a experiência do show de forma mais subjetiva. Pesquisei bastante sobre o disco que a turnê de Amarante busca expor. Me envolvi com as letras de forma bastante subjetiva. A maioria das músicas do disco eu já conhecia, mas pude me aprofundar mais em sua poética graças ao momento anterior ao show em que busquei ler as letras com mais atenção, como forma de me preparar melhor para o trabalho de campo.

A busca por melhor objetivar a situação do show, a partir de um contato mais íntimo com as letras, acabou por subjetivar mais intensamente a minha experiência. Creio que a música e as artes em geral possam causar este efeito "contrário" no cientista social. Ao buscarmos um aprofundamento mais objetivista, corremos o risco de incorparar ou assimilar as obras artísticas de forma mais emotiva do que intelectual. Nestes casos, interesse objetivo (objetivante e científico) e interesse subjetivo correm o risco de serem indissociáveis. Ao ver algumas entrevistas do cantor pude compreender melhor o tema desse seu primeiro disco solo, que se chama Cavalo, com todas as suas implicações poéticas, estéticas, ideológicas e até religiosas.

Ainda no lado de fora do Circo Voador, encontrei na fila de entrada alguns conhecidos. Eles me passaram as suas impressões sobre o disco, que consideram um tanto "deprê", apesar de reconhecerem a sua qualidade. De fato, as músicas são bastante intimistas (com exceção de duas ou três) e "arrastadas", como disse também um dos conhecidos. São inclusive lentas e atmosfericamente pesadas. Isto, em termos propriamente musicais, significa que as canções apresentam andamentos lentos, que a percussividade é menos contínua, que existem mais efeitos percussivos do que "levadas" constantes e que efeitos eletroacústicos propiciam uma atmosfera mais espacial, como se os músicos estivessem tocando em gravidade zero. Não há a presença de baixo elétrico em muitas músicas, o que, aliado à ausência de ritmos contínuos, gera ainda mais uma sensação de flutuação e de falta de "chão".

A letra, graças a esses recursos musicais, ganha mais ênfase e o canto passa a ser o elemento que orienta ritmicamente a música. Uma voz de timbre mais comum, despretensiosa - como diriam alguns críticos musicais - em termos de técnica vocal e de sofisticação timbrística contrasta com certa imaterialidade ou irrealismo gerado pelos recursos instrumentais. Eu estava imerso em todo este clima. As pessoas ao meu redor também pareciam compartilhar esta 
sensação que era um misto de inebriação mística com deleite estético. Não havia, como nos outros shows, gritos de exaltação extasiante vindos da plateia. Os que ocupavam a parte da frente da plateia, bem próximos do palco, cantavam as letras com bastante vigor e ênfase, porém a emoção coletiva geral que emanava parecia rodear mais em torno de uma contemplação atenta do que em torno de uma alegria festiva.

Um momento específico me chamou bastante a atenção. Na verdade, dois momentos específicos que envolviam um grupo pequeno de pessoas. Havia um grupo com cerca de cinco pessoas, aparentemente amigos. Estavam bem próximos de mim, bem na parte central da plateia - no local que funciona como uma espécie de segundo palco. Em um primeiro momento, uma das meninas que estava nesse grupo colocou uma mão para cima com um isqueiro aceso. É muito comum encontrar em shows, de diversos tipos e estilos musicais, esse hábito coletivo de levantar uma das mãos com um isqueiro aceso e balançar o braço de um lado para o outro. Talvez isto não ocorra tanto nos dias de hoje. Nos anos 90 era bem comum. Creio que este ato, hoje, ocorre menos com isqueiros e mais com celulares. As pessoas substituíram os isqueiros pelos celulares. Não falo exatamente sobre as que tiram fotos ou filmam. Me refiro àquelas que usam os celulares como forma de gerar um efeito de luz cuja autoria não diz respeito nem à produção do show nem aos artistas, mas ao público. Nesses momentos, o público, de forma bastante evidente, faz parte tanto da arte cenográfica quanto da arte de iluminação do espetáculo. Talvez esta seja a prova mais visual e explícita de que público e artistas estão sempre engajados para dar o sentido ritual dos espetáculos e eventos que envolvem música ao vivo.

Entretanto, nesse caso específico da moça que levantou o isqueiro no show do Rodrigo Amarante temos uma situação um tanto diferenciada. Somente ela se manifestou desta forma. Ninguém mais levantou um isqueiro aceso como forma de demonstrar agrado em relação à música tocada. Somente essa moça. Nem os amigos que estavam em seu grupo. Podemos imaginar que a moça tivesse a intenção de iniciar um ato coletivo onde algumas outras pessoas iriam levantar também os seus isqueiros para fazer um espetáculo à parte e, ao mesmo tempo, complementar ao show.

Podemos pensar que ela queria ser a precursora desse ato coletivo. Porém, depois de alguns segundos em que viu que ninguém mais aderiu à sua proposta, ela não se enfraqueceu e continuou mais algum tempo com a mão para cima e com o isqueiro aceso. Talvez todos ali, e inclusive ela mesma, soubessem que levantar isqueiros acesos não é algo que ocorra com tanta naturalidade nos dias de hoje. Talvez as pessoas que poderiam ter levantado os seus isqueiros compartilhassem a opinião de que levantar isqueiros em shows já "passou de moda" ou que é 
uma atitude "brega". De fato, parece sim, uma atitude fora de moda. Talvez esse modo de agir não tenha tanta importância para o público frequentador do Circo Voador. Enquanto grupo social mais ou menos homogêneo, em termos estéticos e ideológicos, estas pessoas não manifestaram seu agrado diante das músicas com o auxílio deste recurso. Manifestaram de outras formas.

O que deve chamar mais a atenção é que, consciente da não adesão dos outros ao ato coletivo que supostamente tentou dar início, a moça deu continuidade a sua empreitada fracassada. Mas será este de fato um ato fracassado? Será que consciente mesma da inadequação de seu ato, a moça não deu continuidade a ele justamente como forma de ironizar atos deste tipo? Ou como forma ressaltar o fracasso previsto de sua empreitada? Será que o sucesso do seu brevíssimo projeto não esteve justamente presente logo que ela mostrou que atos deste tipo não são mais bem sucedidos? Em outras palavras, será que no lugar de pensarmos que o seu ato não foi bem sucedido na empreitada de criar adesões, não devamos, ao invés, pensar que ela obteve sucesso justamente por ter permanecido solitária? Existe grande chance de esse ter sido um ato de ironia. Uma ironia branda. Uma ironia não direcionada ao artista, mas sim às pessoas que promovem atos dessa natureza. Em torno desse ato da moça do isqueiro, podemos falar em expressão do gosto, seja ele inato, contingente, individual ou socialmente apreendido? Podemos tratar essa expressividade como sendo o significante de um gosto, de um sentimento, de uma emoção interior, de uma substância permanente ou de um construto socialmente incorporado?

Esse ato - se o considerarmos como um ato criativo de ironia - não é como o significante de um referente. Se ele possui algum referente, este é a ironização, a oposição ideológica, o engajamento intelectual, assim como certo interesse sócio-lógico pelo Outro. Não há, aqui, subordinação de um signo a um elemento extralinguístico. Se há qualquer referente ele é a intersubjetividade, a interlocução. Ele faz referência a um embate político e sócio-lógico entre diferentes ethos e também a uma organização externa (e nem tanto interna). Esse ato do isqueiro não representa uma referencialidade que envolva o par dicotômico essência versus aparência.

Esse ato é um bom exemplo da microfísica da política. Ele não é o produto de qualquer estado interior pré ou extralinguístico. Ao contrário, ele é o gerador de um sentimento cômico que surge em resposta à ironia implícita. Ele é ironia por ser consciente e é consciente por ser irônico.

Outro momento muito curioso para a nossa reflexão foi o que envolveu o mesmo grupo. O mesmo grupo de cinco pessoas, mais ou menos, de que fazia parte também a moça do 
isqueiro. Em uma das músicas mais fortes, profundas e intimistas do show, três pessoas deste grupo levantaram os braços e fizeram uma coreografia que é bastante comum em shows e que consiste em balançar os braços de um lado para o outro, no andamento da música, quase sempre como demonstração de agrado ou mesmo de comunhão entre o espírito da música e o estado de espírito dos que a ouvem. É um gesto muito simples, que todos nós nos acostumamos a ver em diversos momentos. Levanta-se os dois braços, balança-os do lado esquerdo para o lado direito, consciente de que nesse momento se está fazendo parte de uma prática de recepção bastante explícita. Reconhece-se também que ao proceder desta forma se está fazendo parte de uma coreografia bastante espontânea, porém não menos coletivamente determinada.

Existem características estéticas e poéticas próprias às músicas que tanto desencadeiam quanto autorizam simbólica e ritualmente coreografias como essa - considerando que a percepção diante de determinadas características musicais próprias para se responder com atos dessa natureza seja algo socialmente estabelecido e aprendido, isto é, considerando que é preciso ter sido familiarizado com a noção (semi-imperativa) de que enquanto público deve-se responder de determinada maneira a estímulos vindos dos artistas. Além de demonstrarem que estão conectadas emocionalmente com a música tocada naquele momento, as pessoas que aderem a essa coreografia parecem querer demonstrar seu reconhecimento diante de alguns elementos estéticos ou poéticos. São músicas "lentas", emotivas, geralmente hits, músicas mais conhecidas, que consagraram tais artistas, músicas mais "bregas", em suma, músicas onde a emotividade do eu lírico (ou da persona) do artista é mais explícita. O público, como forma de demonstrar reconhecer toda essa carga sentimental, responde ao artista com essa coreografia, que confirma simbólica e ritualmente o sentimentalismo tácito.

Pois o que chamou mais à atenção foi que, no show inteiro, somente esse grupo de três pessoas buscou promover essa coreografia. Somente três deles levantaram seus braços e, de forma sincronizada, balançaram-nos de um lado para o outro. Isto ocorreu em um único momento do show. Talvez outros momentos desta categoria tenham ocorrido em outros pontos da plateia e eu os tenha simplesmente perdido. O principal a se entender é que a coreografia não ocorreu na sua forma clássica, quer dizer, não ocorreu em sua forma mais popularizada. Não foi um gesto da plateia inteira, nem sequer de grande parte dela. Foram gestos isolados (caso tenham ocorrido em algum outro ponto da plateia). Isto nos remete ao que foi discutido acima sobre o componente irônico ou paródico referente aos atos que aparentemente demonstram agrado ou que supostamente sugerem deleite estético vindo de pessoas em plateia. 
Podemos pensar sobre o alto grau de ironia que existem em atos como o do isqueiro ou o dos braços balançando. Os três amigos estavam apenas parodiando atos como esse. Poderiam estar querendo demonstrar, pelo efeito inverso que possui toda ironia, que não é próprio de suas condutas ou de suas personalidades expressar o sentimento de agrado daquela forma. Eles estavam, provavelmente, parodiando a prescrição social predominante relativa à imposição de determinados padrões de expressividade coletiva.

Alguns dos demais integrantes que estavam na plateia e que não aderiram em momento algum a coreografia podem estar subjetiva e coletivamente mais propensos a efetuar gestos como esse do que os que de fato fizeram - e que só o fizeram como paródia, motivados pela ironia. Este tipo de representação não é como a que é analisada por Goffman, no sentido de que o indivíduo não está empenhado em demonstrar atributos que serão aprovados por uma plateia ${ }^{2}$. Eles não estavam ocupados em esconder propriedades pessoais que são condenadas pelos demais participantes daquela interação. Não estavam buscando teatralizar suas condutas de modo a despertar o consenso interacional sobre possíveis qualidades de que dispõem. Ao contrário, eles correram o grande risco de os seus atos de ironia e parodia serem (mal) interpretados como "bregas", "clichês", e serem considerados, em consequência disso, outsiders. Nesse tipo de ato os indivíduos que o realizam correm sempre grande risco de suas paródias se voltarem contra eles próprios gerando assim o efeito contrário do que foi pretendido.

Nesses atos de parodiação e de ironização não está necessariamente presente o par dicotômico, tão defendido por Erving Goffman, que envolve metáfora versus literalidade ou falsidade versus verdade. Vemos em Goffman duas formas de as condutas sociais ocorrerem: 1) como metáfora - com níveis variados de condenação em torno da falsidade e da impostura que remete um significante comportamental a um significado socialmente valorizado. Neste caso, condutas engendram representações que unem, de forma estratégica, o ator social à determinada identidade simbolicamente relevante. 2) como atos literais, que comportariam um forte componente de veracidade em relação e em comunhão com sentimentos e estruturas de personalidade verdadeiras. Essa distinção é bem explícita em Goffman, que concentra suas

\footnotetext{
2 Me refiro a sua teorização em torno da "representação", como a que há em A representação do eu na vida cotidiana (2013). Em Os quadros da experiência social (2012), Goffman apresenta de forma mais clara a possibilidade de que dispõem os atores sociais de, por meio de um ato deturpado ou trazido de outro contexto (tonalização), demostrarem aos observadores o oposto (ou pelo menos o diverso) do que realmente reivindicam. Nesta última obra, Goffman considera de forma mais explícita o costume que possuímos de buscar aprovação por meio do manejo intencionalmente equivocado de atos e expressões que não se adequam ao contexto interacional presente.
} 
análises nas rupturas a que estão sujeitas as representações e encenações cotidianas falseadas, apoiando-se até certo ponto na ideia de haver uma identidade verídica por detrás de toda dramaturgia interacional.

O par fundamental, honestidade versus falsidade, está bem explícito quando Goffman afirma que "por causa destas contingências dramáticas compartilhadas (isto é, da possibilidade sempre inerente da ruptura e do desmantelamento da encenação gerados por atos descuidados) podemos estudar com proveito as representações completamente falsas para aprender alguma coisa a respeito das que são inteiramente honestas." (2013:79). Creio também que não podemos explicar estes atos de parodiação a partir - unicamente - da crença de Arlie Hochschild na literalidade das condutas que expressam emoções. Hochschild parece crer que a literalidade dos atos (que relacionaria de forma precisa expressões emotivas a aspectos reais da intimidade do agente), e não somente a sua metaforalidade, pode ser contextualmente desencadeada. Hochschild, para além da teoria goffmaniana, defende que as emoções demonstradas por motivações rituais e/ou estratégicas podem de fato se manifestar na intimidade do ator social. A autora defende que emoções teatralizadas por motivos contextualmente estabelecidos e estimulados, emoções que precisam de todo um aparato expressivo para serem bem recebidas por interlocutores também podem se dar de forma literal e genuína. Como vimos, para Hochschild, o trabalho de teatralização das emoções não exclui a possibilidade de estas emoções serem íntima e verdadeiramente vividas. Dito de outra forma, as emoções verdadeiramente vividas precisam, elas também, de um trabalho expressivo que envolve a teatralização.

Com efeito, todos os atos de parodiação observados neste dia (e, também, os referentes aos catadores de latinhas do terceiro dia do trabalho de campo) são expressões que estão para além do universo emotivo. Crer que a reflexão sobre o campo emotivo dá conta de explicar os atos relativos às práticas de recepção artística é reduzir o alcance das capacidades expressivas dos atores sociais. Em uma plateia, a expressividade não remete exclusivamente ao universo emotivo do agente. É preciso desromantizar a relação entre o artista e seu público, ou mesmo entre a arte e o uso que dela fazemos. Esses atos de ironia e de paródia dizem respeito a nossa capacidade de sermos conscientes diante da linguagem corporal de que dispomos enquanto seres socialmente configurados.

A configuração social do indivíduo não significa que este seja um ser que vive sob o permanente estado de hipnose ou de transe. Uma paródia expressiva possui, justamente, a função de comunicar o conhecimento que os agentes sociais têm sobre a arbitrariedade da 
expressividade coletiva. Ela revela a consciência de que expressões coletivamente significadas devem ser escolhidas em momentos determinados e que temos mais clareza do que obscuridade quanto a estas escolhas. Revela também que somos capazes de subverter determinações coletivas e sociais. Uma paródia expressiva mostra o agente social enquanto diretor/autor de expressividade e não somente enquanto ator. Ele não só possui consciência do papel que assume - que seria o "ator cínico" de Goffman - (ou consciência de que assume um papel), como possui consciência também de que utiliza essa atuação para afirmar a consciência que tem diante da escolha dos papeis sociais. $\mathrm{O}$ caso dos três rapazes balançando os braços demonstra bem esta afirmação de autoconsciência. Ao agir de forma paródica eu não só reconheço - intimamente que sou um ator, mas também mostro para os outros que eu só ajo desta forma, caricata e deslocada, porque possuo consciência de que assumo papeis sociais. Mostro para os outros que possuo consciência de que há papeis sociais a serem assumidos. Com a parodia expressiva ironizo, ao mesmo tempo, um papel social e o costume que temos de assumir papeis sociais.

A paródia é o grito da (auto)consciência. Nem habitus, nem inconsciente, tampouco estrutura. Paródia é ação politica, consciente, engajada, que revela o agenciamento enquanto postura intelectual, que se encontra na superfície e não nas profundezas da mente humana. As pessoas não só falam entre aspas, ou seja, elas não só discursam ironicamente, falando como se fossem os outros (ou o Outro), falando com o intuito de parodiar os outros, falando conscientemente a fala que atribui aos outros. $\mathrm{O}$ afastamento ideológico, de opinião ou de crença através da citação irônica do que seria a fala do Outro não se dá apenas pela linguagem escrita ou falada. As pessoas agem entre aspas. Elas agem ironicamente, como forma de ilustrar a ação que seria de outros ou que seria vinda de um imaginário sobre os outros ou sobre ela mesma. As pessoas agem ironicamente buscando por sob dúvida a representação coletiva que se tem dela e de seu grupo social. Agimos, muitas vezes, como forma de parodiar a representação dominante que se tem do grupo social a que pertencemos. Algumas vezes agimos de forma exagerada ou deturpada justamente para negar (ou ao menos relativizar), conscientemente, a naturalidade de tal ação que é comumente atribuída a nós mesmos e ao nosso grupo.

Quando estou em um show de heavy metal, por exemplo, e ajo de forma estereotipada com as duas mãos para cima fazendo o símbolo do diabinho, com cara de mal, posso estar justamente negando que este padrão de comportamento estereotipado seja um modo de agir natural meu - ou mesmo que este ato tenha sido "socialmente internalizado". Posso sempre fazêlo entre aspas. Entre aspas de afastamento, como diria Viveiros de Castro. Estarei, assim, agindo 
entre aspas. Estarei ironizando o padrão de conduta que se espera de mim, principalmente se o faço de forma evidentemente teatralizada.

Se uma única moça, em meio a uma plateia com cerca de quinhentas pessoas, acende seu isqueiro e balança para um lado e para o outro as mãos como forma de teatralizar uma conduta referente a outros tempos ou outros grupos sociais, esta não é nem uma expressão do seu "gosto pessoal" nem tampouco um ato socialmente "internalizado". Esse ato específico representa o seu intuito de ironizar, de parodiar uma conduta que é, justamente, socialmente esperada e atribuída. Tende a ser paradoxal demarcar sociologicamente uma conduta como essa, que visa justamente contrariar expectativas sócio-lógicas. Paródias expressivas buscam exatamente objetivar (por meio da ironia) as estereotipações de caráter socio-lógico.

Quanto mais óbvia e exagerada é a marca social de um ato, menos socio-lógica pode ser a sua motivação. Os agentes podem querer contrariar a sociologicidade estrita dos atos através de ironias e paródias direcionadas a estereótipos simplistas que partem do senso comum. Se fosse tão sociologicamente motivado o ato de ironia da moça no show do Rodrigo Amarante e se ela estivesse inserida em um grupo social de fato homogêneo, encontraríamos um padrão de atos como esse na plateia deste dia de forma mais generalizada. É certo que a sua motivação individual pode representar um quadro mais amplo de conflito ético-estético entre grupos que levantam isqueiros em shows e grupos que não levantam, entretanto, é preciso considerar que atos desse tipo não podem ser facilmente relacionados a grupos sociais demarcados.

Com efeito, a ironização/parodiação realizada pela moça no show do Rodrigo Amarante pode não ter como alvo a representação de um grupo social específico. Ela pode querer denunciar uma relação de poder ou um poder enquanto relação (como afirmaria Foucault). Ela pode querer questionar justamente a obrigatoriedade da aparição de momentos como esses em shows. Paródias expressivas como essas podem querer ferir a facilidade com que emergem em quase todos os lugares atos coletivos como os do isqueiro.

Recebido em: Julho de 2016 Aprovado em: Novembro de 2016 